Thirty people were injured by falling off the castle (17 male, 13 female; five aged $0-4,12$ aged 5-9, 12 aged 10-14, and one aged 22). Parts of the body commonly injured were the foot, ankle, or toe (10 cases) and the arm, elbow, wrist, or hand (eight cases). Most injuries were minor bruising, cuts, or swelling (20 cases), but there were six fractures and three sprains or strains. Two children required admission for fractures to the arm or elbow. The locations of the bouncy castles varied: six were at fairgrounds and five at indoor sports centres.

Seventy five people were injured on the castle itself ( 31 male, 44 female; eight aged 0-4, 33 aged 5-9, 27 aged 10-14, and seven adults). Thirty two fell over and 14 were struck by another child, usually after the patient had fallen over. The arm, elbow, wrist, or hand (27 cases), the face and neck (nine cases), and the ankle or foot (15 cases) were commonly injured. Fifty injuries were minor, with nine fractures, 10 sprains and strains, and two dislocations. Fairgrounds ( 10 cases) were the most common site for the castle.

The youngest child injured was 2 and the oldest adult 41 . Only one adult was not actually playing on the castle at the time of injury.

The severity of injuries resulting from people falling off bouncy castles could be reduced by surrounding the castles with impact absorbing matting. The frequency of other injuries could be reduced by controlling the number of children playing on the castle at any time. Adults were injured by doing somersaults, diving over the castles, and throwing one another around; they should contain their exuberance when playing on these castles.

Child Accident Prevention Trust,

London W1N 4DE

1 Singer G, Freedman LS. Injuries sustained on "bouncy castles." BMF 1992;304:912. (4 April.)

\section{Is the child father of the man?}

SIR, - Roger J Robinson's editorial draws attention to the work done by David Barker and his team in relating coronary risk factors and cardiovascular risk in middle age to factors operating in the uterus and in infancy. ${ }^{1}$ The inability of known risk factors measured in middle age to explain all that they might has been widely recognised. It has led, over the years, to many extravagant claims by research lobbies that, given funds, they would close the gap and supply the missing links, whether they are lipid subfractions, psychosocial factors, or DNA sequencing.

The Southampton group has rendered a service in opening up another dimension for environmental determination of cardiovascular risk and, by implication, for prevention. The editorial suggest that these findings have changed the paradigm for explaining regional variation in disease. Whether or not this is true, they cannot explain the other contemporary conundrum: the dramatic declines in mortality from coronary heart disease that are occurring in many countries. These support the role of environmental influences now.

The figure shows trends in mortality from coronary heart disease in men in the United States and in England and Wales, using a logarithmic scale to permit simultaneous comparison of eight different age groups. If the declining trends were caused by beneficial changes in exposures in early life they should occur in the youngest age group first and take three decades to work through from the 35 to the 65 year olds. In the United States the curves all began to turn over and plunge almost in unison in the middle to late 1960s (the blip in 1979 was due to a change in rules on coding disease). In England and Wales there is indeed a vague suspicion that older age groups are changing later,
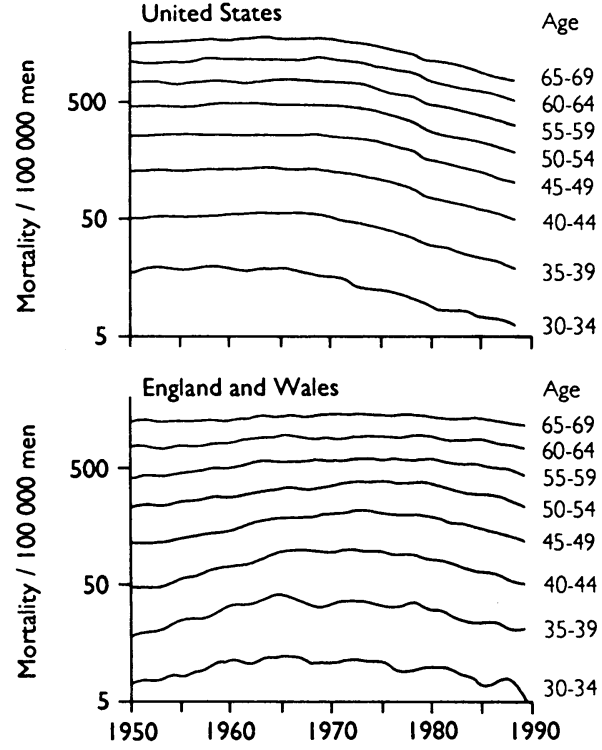

Mortality from coronary heart disease (100000 men in United States and England and Wales (from data of World Health Organisation analysed by cardiovascular epidemiology unit, Dundee University)).

but not enough to fit the birth cohort model described above. In general, within each age group, rates in England and Wales oscillated on a plateau between 1965 and 1975 before declining in the 1980s.

Despite the importance of the work done in Southampton cardiovascular risk can still be modified quite profoundly, even after subjects have graduated from the uterus and are out of nappies.

HUGH TUNSTALL-PEDOE

Cardiovascular Epidemiology Unit,

University of Dundee,

Ninewells Hospital and Medical School,

Dundee DD1 9SY

1 Robinson RJ. Is the child father of the man? $B M \mathcal{F} 1992 ; 304$ 789-90. (28 March.)

\section{Patent foramen ovale and subaqua diving}

SIR,-Would the $B M \mathcal{F}$ publish a study which suggested that hypertension is not a risk factor for stroke because the authors had found 26 hypertensive patients who had not had a stroke? Probably not. Yet Stephen J Cross and colleagues' report on the safety of subaqua diving for people with a patent foramen ovale is based purely on their observation that 26 divers with intracardiac right to left shunts on contrast echocardiography had not had decompression sickness.

Although such a shunt will usually correspond with a patent foramen ovale, not all people with a patent foramen ovale will have shunting and some shunts will be due to other mechanisms. Any comparison between the incidence of shunts during life and the incidence of patent foramen ovale in a necropsy study must be approximate. ${ }^{2}$

We know from larger studies that a significan proportion of divers who have never had decompression sickness have shunts. ${ }^{3}$ This is only to be expected. Shunts occur in a quarter to a third of the population, and there is no obvious reason why the presence of a shunt would affect recruitment of divers. Thus about 15000 of the 50000 divers in the United Kingdom might be expected to have shunts. Even if each of the 100 cases of decompression sickness annually in the United Kingdom occurred in divers with shunts there must be many divers with shunts who do not get decompression sickness, and other factors must also operate. Clearly, to show that shunts are a risk factor for decompression sickness by showing a reduced incidence of shunts in unaffected subjects a study would need to be exceedingly large. It is far better to examine the incidence of shunts in affected people. ${ }^{4}$

Cross and colleagues question "whether these shunts are relevant in subjects who have not had decompression sickness." Is hypertension a risk factor for stroke in someone who does not have a stroke?

The authors conclude that "the presence of a shunt in a diver without a history of decompression sickness may be irrelevant" and that "there is probably not a case for routine screening of divers for shunts" (my emphasis). If their data do not give a definite answer it is equally valid to conlude that the presence of a shunt may be relevant to divers who will one day get decompression sickness and that there is possibly a case for screening.

PETER WILMSHURST

Huddersfield Royal Infirmary,

Huddersfield HD3 3EA

1 Cross SJ, Evans SA, Thomson LF, Lee HS, Jennings KP Shields TG. Safety of subaqua diving with a patent forame ovale. BMF 1992;304:481-2. (22 February.)

2 Hagen PT, Scholz DG, Edwards WD. Incidence and size of patent foramen ovale during the first 10 decades of life: an autopsy study of 956 normal hearts. Mayo Clin Proc 1984;59:17-20.

3 Wilmshurst PT, Byrne JC, Webb-Peploe MM. Relation between inter-atrial shunts and decompression sickness in divers. In Sterk W, Geeraedts L. EUBS 1990 proceedings. Amsterdam European Undersea Biomedical Society, 1990:147-53.

4 Moon RE, Camporesi EM, Kisslo JA. Patent foramen ovale and decompression sickness in divers. Lancet 1989; ;:513-4.

5 Wilmshurst PT, Byrne JC, Webb-Peploe MM. Relation betwee inter-atrial shunts and decompression sickness in divers. Lancet 1989;ii:1302-6.

AUTHORS' REPLY,-About half of divers with decompression sickness are found to have right to left shunts. ${ }^{12}$ As Peter Wilmshurst states, roughly 15000 of the 50000 divers in the United Kingdom would be expected to have a shunt, yet there are only 100 cases of decompression sickness each year. Although a right to left shunt may increase the risk of a diver developing decompression sickness, this additional risk should not be exaggerated.

STEPHEN J CROSS HAI SHIANG LEE LESLEY THOMSON KEVIN JENNINGS Departments of Cardiology and Anaesthetics, Aberdeen Royal Infirmary Aberdeen AB9 2ZD

SIAN EVANS THOMAS SHIELDS

Hyperbaric Research Unit,

Robert Gordon Institute of Technology, Aberdeen AB9 1FR

1 Wilmshurst PT, Byrne JC, Webb-Peploe MM. Relation between interatrial shunts and decompression sickness in divers. Lancet 1989;ii:1302-6.

Moon RE, Camporesi EM, Kisslo JA. Patent foramen ovale and decompression sickness in divers. Lancet 1989; i:513-4.

\section{Site distribution of colorectal cancer}

SIR,-It is often stated that about $70 \%$ of colorecta tumours are within reach of a flexible sigmoidoscope. This has been reiterated in the ABC of Colorectal Diseases' but may be an overestimate Widespread evidence suggests that the site distribution of colorectal cancer is altered in countries in which there is a high incidence of colorecta cancer. ${ }^{23}$

We have examined the site distribution of the 487 histologically proved colorectal cancers newly diagnosed in Northern Ireland in 1990. This information was available from the database of the Northern Ireland colorectal cancer register. A tota of 231 cancers $(47 \cdot 4 \%)$ occurred in the proxima colon and beyond the $60 \mathrm{~cm}$ range of the flexible sigmoidoscope.

Northern Ireland has one of the highest inci- 